\title{
Movement Remote Command and Control in the Military Technical Systems through the Inferential Method
}

\author{
Dumitru GRIGORE, \\ Technical Military Academy Bucharest, George Coşbuc Boulevard, no. 39-49, \\ Sec. 5, Bucharest, 050141 \\ dumitru.grigore@psychometricsystems.com
}

\begin{abstract}
The research described in the paper at had approaches the interaction between the bio-signal and the remote movement control, by introducing an original mathematical model, regarding the psychophysiological inference from the EDA response bio-signals. The experiments were performed using an adequate design, consisting of two different techniques regarding bio-signals, in order to obtain, in variables corresponding to each of them, the same type of electrical behaviour. In order to establish the projective functions, a direct measurement method was used on the levels of potential in the epidermis's alternative current, of base- (SPL) and response-type $(S P R)$, the acquisition being executed with an integrated technical system, patented by the author in year 2013.

The statistical study targets the correlation analysis of the action of multiple stimuli on the EDA functions, respectively the analysis of the multiple correlations between the EEG and EDA patterns. Necessary in sending the remote command and control of a movement, this correlation in the electrical signal can be implemented in the BCl-type systems, offering superior possibilities of using the bio-feedback systems.
\end{abstract}

Keywords: bio-signals; electro-dermic response; correlation; $\mathrm{BCl}$ systems; command and control; bio-feedback

JEL Classification: O31.

\section{Introduction}

Applicative research in neuro-engineering, cognitive engineering and cognition sciences occupies an important place at the international level. At present, for the study of the brain, are use advanced techniques and technologies, among which, notable is magnetic resonance imagistic. It offers precious information on the areas of the brain activated under the action of the 
stimuli, images which, reproduced through evocation, confirm and certify the concept of pattern recognition, being particularly useful in the mapping procedures. Also for the purpose of mapping the brain the electroencephalography (EEG), techniques are also used, but with lower resolution.

All these experimental research aspects gain coherence and sense under the auspices of the new concept of neuro-engineering, with its implementation opportunity in neuro-technology. It stands out according to all interdisciplinarity criteria generically assigned to techno-psychology, being based on the studying of the relationship between the neurons, the neural networks and the functions of the nervous system, and on the passing to the quantifiable models, for the purpose of developing and implementing technical devices for signal measurement and control.

Another phenomenology very much used on the measurement systems of psycho-physiological aspects is the electro-dermal activity (EDA). It will also be seen in case of the well-known polygraph (lie-detector), being also at the basis of many measurement instruments, by means of which in the last 30 years a series of important psycho-physiological determinations have been made.

However, all this research does not succeed in going through all complex aspects necessary for the inference outlining from physiological data of a satisfactory complex of cognitive aspects, which can be involved with sufficient certainty in the movement remote command and control in the technical systems.

The research presented in the article at hand cannot be exhausted in the field of a single discipline. Thus, from the signal physics and the mathematics of their processing, until the psycho-physiological phenomenology expressed in an advanced form of patterns, whose functions for remote movement command and control presuppose also elements of electronic and electro-mechanic engineering, the topic proposed requires a sustained and argued multidisciplinary approach.

Such approach presupposes the study of the interface phenomena, which can offer engineering the possibility to implement the command and control elements, using at entry the neuro-signals acquired through specific procedures, corresponding to certain psycho-physiological aspects. In this sense, particularly important is the modeling formula selected for executing the command and control system algorithm. 
The research at hand displays a global vision on the identification solutions of the psycho-physiological elements involved in command and control algorithms, executed on a direct, non-invasive, rapid and very precise method measurement technology.

The working method provides the opportunity to identify and manage in an experience database of invariant cognitive structures, for subsequent correlations in developing the remote command and control algorithm, thus bringing in the paradigm of the man-machine interface innovative solutions regarding the contribution of the cognitive typologies, respectively the specific psychological conditions, necessary in the remote actuation of technical systems.

Following its own path, by means of the niche application it develops, our research opens the perspective of implementation in the technical military systems of intelligent interfaces which to involve the human brain directly in the management of remote commands. For this purpose, the procedure of "phasic epidermis neuro-stimulation" was used in an original concept, together with equipment and a method capable of identifying very rapidly the psychological profile, all patented by the author (Grigore, 2013).

The main goal of the paper aims to determine the correlations between the bio-signal patterns, distinct as physiology and acquired with distinct equipment.

Applicability in the military field: the benefit of using remote movement command and control solutions in the military technical systems - object of the research at hand - consists in the increase of the individual and group security in exploiting these systems, with applicability in case of the aiming devices, of the remote-controller robotized systems, in order to pass from the real to the virtual battlefield, with immense benefits regarding the safety of the military staff and of saving human lives. Also, the original mathematical inferential model proposed to identify the cognitive classes, as well as the algorithm implemented in the software, constitute a particularly safe and viable instrument in the selection of the military staff operating $\mathrm{BCl}$ interfaces.

\section{EDA phenomenology in psychophysiology}

Part of the peripheral nervous system, the Autonomous Nervous System (ANS) fulfils, first of all, the regulation function, with a fundamental role in ensuring homeostasis. The changes occurring in the ANS activity can also be 
assessed by means of measuring the electro-dermic activity (EDA), which is the manner most often used in psychological research.

The electro-dermic response appears when between two electrodes applied on the skin there is a difference of potential sufficiently small for the experiment to be non-invasive. Between them, an electrical current will occur, through the epidermis area, based on which one can measure the reactive, information-carrying SCR phasic conductance (Grigore, 2014). In the absence of electrical current, SCL tonic conductance, a basal conductance, manifests. "Specific EDR is viewed as a peripheral manifestation of neuronal activation, triggered by requirements on the cognitive capacity", according to the voluntary control hypothesis (Öhman, Hamm, \& Hugdahl, 2000), reflecting a requirement of additional processing resources.

Edelberg distinguishes between the persons with electro dermal lability and the stable ones (Edelberg, 1968). This attribute can be correlated with a series of inferential variables in psycho-physiology, on the grounds of electro dermal lability and stability making a differentiation between the traits of individuals. Epidermal lability is a factor which can strongly influence the cognitive indicators. The intelligence indicator, for example, is strongly correlated with low epidermal lability, while a high lability indicates a low availability faced with cognitive loads.

Epidermal conductance in its phasic aspect is the effect of the activity of the sweat glands (eccrine), such as, when they abundantly produce, phasic changes occur in conductance; respectively, when the moisture is absorbed, conductance returns to the basic values (Boucsein, 2012). The behavior of the sweat glands, in this sense, can be compared to resistances whose values, inverse to conductance, decrease when the moisture is maximum, respectively, increase when it decreases to normal values, the quantity of solution produced by the glandes, respectively, their number evaluated simultaneously, being in inverse relationship with the amplitude of the conductance change. The activity of the sweat glands is "a projection of the action of the reticular formation of the brain stem, of hypothalamus, of the limbic system and of the motor cortex" (LAROUSSE, 2006).

The method of measuring the electrodermal potential in alternative current is preferable, through the advantage of using monopolar electrodes. In continuous current, these measures call for the use of dipolar electrodes, which can be irritating for the epithelial tissue. The interest parameters in case of measurements of electrodermal potential in alternative current are: base 
potential (SPL) and response potential (SPR), which are considered in the model applied throughout this research (Grigore, 2014).

\section{Remote command through stimulated cognitive patterns}

The approach of the remote transmission of a command, as well as ensuring the control of a movement through the inferential psychic structures of cognitive pattern type presupposes a stimulus-pattern correlation which leads to the interception of the cognitive "behaviour" in a system of coordinates which offers the facility of dissociating the basic aspects involving decision, ensuring the person involved the possibility to administer the control remotely, by biofeedback.

The block diagram of a system remotely transmitting a command, through the stimulus-cognitive pattern correlation, is presented in Figure 1 . Within this system, the most important component is the experience database. It contains all known correlations between the stimulus and the cognitive pattern. In order to extract the facility, the pattern identificatory withholds from the structure of the acquisition bio-data the encoded form of the pattern evoked by the witness stimulus and transmits it to a comparing block which ensures the role of classification, previously programmed with the pattern code of the witness stimulus selected from the experience database. When the code "stimulus" is identical to the code "pattern", the comparing block transmits a valid command to format the command. The remote command is taken by the execution element operating the topic formed at the level of the command and the subject takes control through bio-feedback, involving in the command and control loop the other witness stimuli (Grigore, R2, 2013).

Figure 1. Block diagram for remote movement command and control

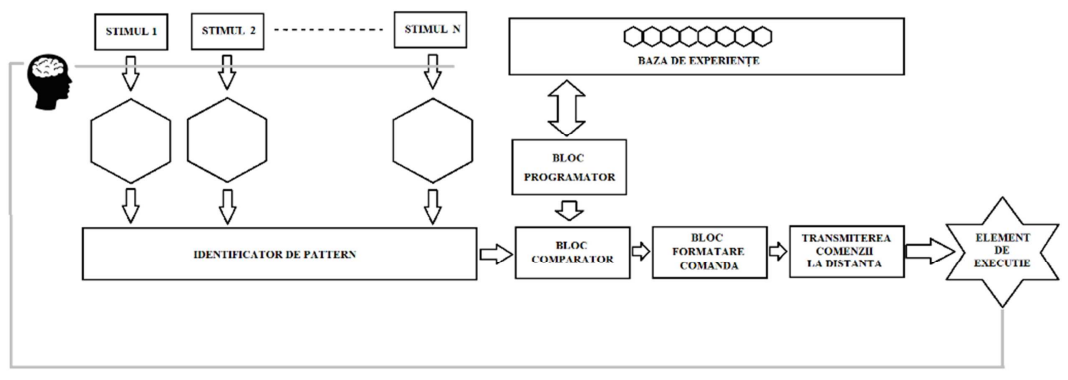

Source: Grigore, R2, 2013, author concept 


\section{Processing method of the EDA neuro-signals}

\subsection{Phasic neuro-stimulation}

Within the studies performed with the phasic neuro-stimulation system (Grigore, 2013), we noticed that, when an alternative tension signal and a step signal are used, for the simultaneous stimulation of the epidermis, in its phasic stage, the level of lability or stability of the electrodermal response can be easily established, at different subjects. The response potential, in this case, in alternative current, is an inferential marker.

This type of stimulation opens projective psycho-physiological correspondences. Thus, the bioelectrical events accompanying the self-regulation processes can be estimated by means of the electrical markers, with sufficient precision (Paraschiv, Grigore \& Constantin, 2013).

The opening of a neurostimulator channel puts the measurement area in correspondence with the targeted psycho-physiological function, and the neural signals collected at the level of the sensors contain information regarding the response pattern for the stimulus applied, information which must be properly analyzed, in order to extract the aspects related to the mental states (Paraschiv, Grigore \& Constantin, 2013).

We approached the neurostimulation procedure from the perspective of the ensemble of signals involved: excitement step signal, response step signal and carrier signal, of sinusoidal form.

The excitement signal is a step-type signal, whose form can be written as follows:

$$
u_{1}(t)=\sum_{k=1}^{N} A_{k}[\sigma(t-k T)-\sigma(t-(k+1) T)]
$$

where the Heaviside function has the form: $\sigma\left(x-x_{0}\right)={ }_{1} ; x \geq x_{0} ; \sigma\left(x-x_{0}\right)=0$; $x \leq x_{0}, \mathrm{~T}$ is the period of the step signal and $\mathrm{A}$ is its amplitude.

The carrier signal can also be written as follows:

$$
u_{2}(t)=A_{S} \cos \left(\frac{2 \pi t}{T_{0}}\right)
$$

where AS represents the signal amplitude and TO its period. 
The response signal. In Figure 2, a and b, are illustrated the signals involved in the epidermis phasic neural stimulation procedure.

Figure 2: Diagram of the signals involved in phasic neural stimulation on a single step impulse: (a) before stimulation; (b) after stimulation

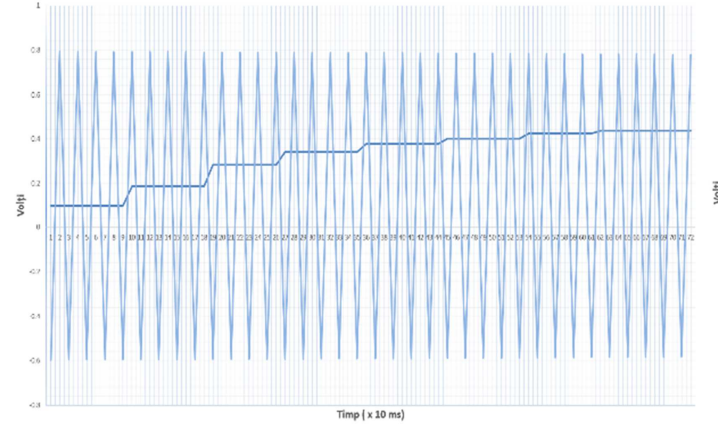

a)

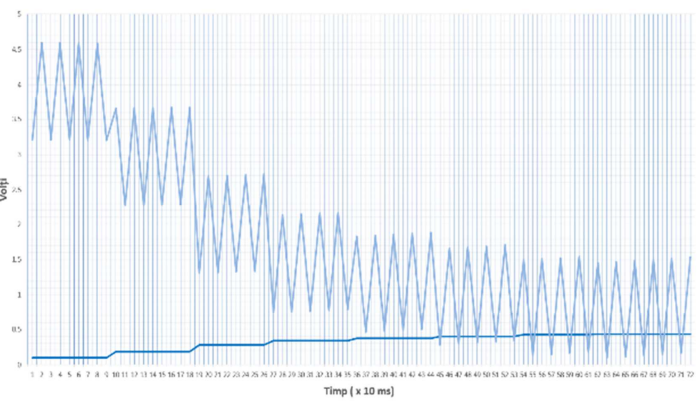

b)

Source: author concept

The form of the result signal is:

$$
u_{\text {Total }}(t)=A_{S} \cos \left(\frac{2 \pi t}{T_{0}}\right)+A_{t} \sum_{k=1}^{N} k[\sigma(t-3 k T)-\sigma(t-3(k+1) T)]
$$

The information regarding the inferential processes is reflected in the structure of this composed signal. In order to perform the experiment in this thesis, we established another variable, $\lambda$, which will designate electrodermal lability, measurable in the frequency of SPR responses throughout an acquisition session (Grigore, 2016).

\section{GSR-type patterns}

Expanding the form of the diagram to the level of $i$ impulses, for a stimulation cycle, we obtain:

$$
u_{i}(t)=A_{S_{i}} \cos \left(\frac{2 \pi t}{T_{0}}\right)+A_{t_{i}} \sum_{k=1}^{N} k[\sigma(t-3 k T)-\sigma(t-3(k+1) T)]
$$




\subsection{The inferential model}

In approaching the mathematical form of expressing the dynamics of the electrodermal potential neurostimulated in alternative current, we represent in Figure 3 the transition of function $u(t)$ from point $A$, where the value of the electrodermal potential response (SPR) is found, to point $B$, where the value of the electrodermal potential level (SPL) is found (Grigore, 2016).

Figure 3: Electrodermal potential neurostimulated in alternative current

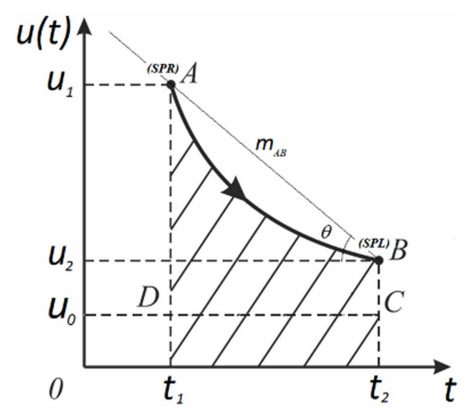

Source: author concept

\subsubsection{Energy allocated}

The process of epidermis neurostimulation in alternative current at the phasic level is performed for the same subject, on several channels simultaneously. The effect that this stimulation can produce, reflected by the transition of the electrodermal potential, is evaluated in power. For each stimulated channel $i$, the form of allocated power is:

$$
P_{i}(t)=I_{i} \cdot u_{i}(t)
$$

where $l_{i}$ is considered constant (facility ensured through the construction of the neurostimulation equipment), such as the energy consumed in the transition to be determined by integrating the relation (5):

$$
S_{i}(t)=I_{i} \int_{t_{1}}^{t_{2}} u_{i}(t) d t
$$

$S_{i}$ having the significance of energy allocated to channel $i$ in the neurostimulation process. 


\subsubsection{Inference level}

We considered that every neurostimulation source, afferent to a channel $i$, achieves a specific inference for a band $j,(\forall) j=\overline{1, n}$. Therefore, we saw in which manner the allocated energy $S_{i}$ manifested in a physiological potential $\varphi$, will cause inference $\gamma$ on a measurement channel $i$ and a band $j$. The relationship between $\varphi$ and $\gamma$ is of the type:

$$
\gamma_{i j}=\beta \cdot \varphi_{i j}
$$

where $\beta$ is a scale factor of the form $\varphi /\left(u_{\max }-u_{0}\right), u_{\max }$ is the maximum potential on the scale used, and $u_{0}$ is the minimum value of the response potential, until which a psycho-physiological inference can be intercepted [Grigore, 2016].

The indicator that characterizes the neurostimulation transition of the alternating current electrodermal potential is parameter $m_{A B}$, defined as the slope of the line containing segment $A B$ (Figure 3). The form of $m_{A B}$ for a neurostimulation channel $i$ can be written as follows:

$$
m_{A B i}=\frac{u_{1 i}-u_{2 i}}{\left|t_{1}-t_{2}\right|}
$$

The significance of slope $m_{A B_{i}}$ depends on the electrodermal response level (SPR), its position being a function directly proportional to the level of psycho-physiological inference. The variation of parameter $m_{A B_{i}}$ can be followed for $u_{1 i}=u_{2 i}$, where $m_{A B_{M I N}}=0$, respectively, for $u_{2 i}=u_{0}$, obtaining $m_{A B_{M A X}}=\frac{u_{1 i}-u_{0}}{\left|t_{1}-t_{2}\right|}$

Considering that every transition from a channel $i$ produces a specific inference on a band $j$, the form of slope $m_{A B j}$ afferent to a band $j$, for a minimum value $u_{0}$ of potential, is written:

$$
m_{A B j}=\frac{u_{1 j}-u_{0}}{\left|t_{1}-t_{2}\right|}
$$


I will define the physiological component $\varphi_{i j}$ of the inferential relation for the channel $i$ and the band $j$, as a product of the SPR potential measured on the stimulation channel and the ratio between the slope of the stimulation channel and the inference band slope:

$$
\varphi_{i j}(u)=u_{1 i} \frac{m_{A B_{j}}}{m_{A B_{i}}}
$$

relation with the aid of which, the form of the inference level (7) becomes:

$$
\gamma_{i j}=\frac{\tau u_{1 i}\left(u_{1 j}-u_{0}\right)}{\left(u_{\max }-u_{0}\right)\left(u_{1 i}-u_{2 i}\right)}
$$

\subsubsection{The inferential function}

In order to establish the form of inferential function $\Psi_{i j}$, we took into account the transition of the electrodermal potential for a channel $i$, the manner in which it causes inference and the average response of the electrodermal potential at the level of all $i$ neurostimulation channels. We defined the efficiency of the neurostimulation process on a channel $i$, as being the ratio between the energy allocated that that channel $i$ and the average of the energies allocated on all channels [Grigore, 2016].

By means of relation (6), we established the form of the average energy allocated on all $i$ neurostimulation channels:

$$
\bar{S}=\frac{I}{i} \int_{t_{1}}^{t_{2}}\left(u_{1}(t)+u_{2}(t)+\cdots+u_{i}(t)\right) d t
$$

where we took into consideration that $I_{1}=I_{2}=\cdots=I_{i}=I$, condition ensured through the construction of the neurostimulation equipment.

From (6) and (12) we deduced, thus, the efficiency for each channel $i$ : 


$$
\begin{aligned}
& \rho_{i}=\frac{I \int_{t_{1}}^{t_{2}} u_{i}(t) d t}{\frac{I}{i} \int_{t_{1}}^{t_{2}}\left(u_{1}(t)+u_{2}(t)+\cdots+u_{i}(t)\right) d t} \\
& =i \frac{\int_{t_{1}}^{t_{2}} u_{i}(t) d t}{\int_{t_{1}}^{t_{2}}\left(u_{1}(t)+u_{2}(t)+\cdots+u_{i}(t)\right) d t}
\end{aligned}
$$

On the other hand, considering that the psycho-physiological inference ratio presupposes the inferential reproduction of an entire ensemble of psychological functions $\Psi_{i j}$, we established that, in order to compose it, the inferential relation between the elements will be of the form:

$$
\psi_{i j}=\rho_{i} \gamma_{i j}
$$

with the meaning of inferential indicators, components with the aid of which, considering (4.130), we wrote the final form of psycho-physiological tensor $\Psi_{i j}$ :

$$
\Psi_{i j}=\frac{\tau}{u_{\max }-u_{0}}\left(\begin{array}{ccccc}
\rho_{1} u_{11} \frac{u_{11}-u_{0}}{u_{11}-u_{21}} & \rho_{1} u_{11} \frac{u_{12}-u_{0}}{u_{11}-u_{21}} & \cdot & \cdot & \rho_{1} u_{11} \frac{u_{1 j}-u_{0}}{u_{11}-u_{21}} \\
\rho_{2} u_{12} \frac{u_{11}-u_{0}}{u_{12}-u_{22}} & \rho_{2} u_{12} \frac{u_{12}-u_{0}}{u_{12}-u_{22}} & \cdot & \cdot & \rho_{2} u_{12} \frac{u_{1 j}-u_{0}}{u_{12}-u_{22}} \\
\cdot & \cdot & \cdot & \cdot \\
\cdot & \cdot & \cdot & \cdot \\
\rho_{i} u_{1 i} \frac{u_{11}-u_{0}}{u_{1 i}-u_{2 i}} & \rho_{i} u_{1 i} \frac{u_{12}-u_{0}}{u_{1 i}-u_{2 i}} & \cdot & \cdot & \rho_{i} u_{1 i} \frac{u_{1 j}-u_{0}}{u_{1 i}-u_{2 i}}
\end{array}\right)
$$

where we identified and re-wrote the form of an inferential indicator $\psi_{i j}$ :

$$
\psi_{i j}=\frac{u_{1 i} i}{u_{\max }-u_{0}} \frac{u_{1 j}-u_{0}}{u_{1 i}-u_{2 i}} \frac{\int_{t_{1}}^{t_{2}} u_{i}(t) d t}{\int_{t_{1}}^{t_{2}}\left(u_{1}(t)+u_{2}(t)+\cdots+u_{i}(t)\right) d t}
$$

\subsubsection{The cognitive function}

The aspects of interest in establishing the cognitive typologies are those regarding the manner in which the inferential indicators reflect in the cognitive 
acts. We will represent the entire ensemble of inferential indicators through a set of cognitive functions on the form:

$$
c=\alpha \cdot \psi
$$

where $\alpha$ represents a weight, as measure of the manifestation level in the cognitive function of the inferential indicator. The tensor of the cognitive functions is composed by the products between the matrix of weights and that of inferential indicators:

$$
C_{i j}=\left(\begin{array}{ccccc}
\alpha_{11} & \alpha_{12} & \cdot & \cdot & \alpha_{1 i} \\
\alpha_{21} & \alpha_{12} & \cdot & \cdot & \alpha_{2 i} \\
\cdot & \cdot & \cdot & \cdot & \cdot \\
\cdot & \cdot & \cdot & \cdot & \cdot \\
\alpha_{k 1} & \alpha_{k 2} & \cdot & \cdot & \alpha_{k i}
\end{array}\right) \cdot\left(\begin{array}{ccccc}
\psi_{11} & \psi_{12} & \cdot & \cdot & \psi_{1 j} \\
\psi_{21} & \psi_{12} & \cdot & \cdot & \psi_{2 j} \\
\cdot & \cdot & \cdot & \cdot & \cdot \\
\cdot & \cdot & \cdot & \cdot & \cdot \\
\psi_{i 1} & \psi_{i 2} & \cdot & \cdot & \psi_{i j}
\end{array}\right)
$$

which becomes:

$$
C_{i j}=\sum_{i=1}^{n} \alpha_{k i} \psi_{i j},(\forall) k=\overline{1, n} ;(\forall) j=\overline{1, n}
$$

\subsubsection{The inferential pattern, cognitive typology}

In order to identify the cognitive typologies, we grouped the elements of matrix $C_{i j}$ according to a number $m$ of polarity criteria, in pairs, and we thus obtained a set of inferential patterns of the form:

$$
S_{p q}=\left|\left(\sum_{i=1}^{n} \alpha_{k i} \psi_{i j}\right)_{p}\left(\sum_{i=1}^{n} \alpha_{k i} \psi_{i j}\right)_{q}\right|,(\forall) p=\overline{1, m} ;(\forall) q=\overline{1, m}
$$

By combining the inferential patterns, we identified a number $\mathrm{t}=m(m-1)$ of cognitive typologies of the form:

$$
V_{x y}=\left(S_{p q}\right)_{x}+\left(S_{p q}\right)_{y},(\forall) x=\overline{1, t} ;(\forall) y=\overline{1, t}
$$

which, in their turn, are grouped in the $m$ cognitive classes. By selecting the weight of the highest value of the amount (4.144), we obtained the most stable cognitive typology (Grigore, 2016). 


\section{The coordinates of the experimental study}

The research refers to the use of two different techniques, which involve bio-signals of different physiologies, in order to obtain in variables corresponding to each separate technique, the same type of cognitive behaviour, expresses in the electrical signal. Necessary in transmitting the remote command and control of a movement, the results of the experiment can be implemented in $\mathrm{BCl}$-type systems, offering higher possibilities of using the systems with biofeedback (Grigore \& Petrescu, 2015; Grigore, Paraschiv \& Anghelina, 2016).

\subsection{Hypothesis and objectives}

It is known that the electrodermal response to conductance is the effect of sweat glands activity. When they secrete abundantly, phasic changes occur, manifested through the increase of conductance, respectively when the moisture is absorbed, conductance returns to the base values. The behavior of the sweat glands, in this sense, can be compared to resistances whose values, inverse to conductance, decrease when the moisture is maximum, respectively, increase when it decreases to normal values, the quantity of solution produced by the glandes, respectively, their number evaluated simultaneously, being in inverse relationship with the amplitude of the conductance change. The activity of the sweat glands is "a projection of the action of the reticular formation of the brain stem, of hypothalamus, of the limbic system and of the motor cortex" (LAROUSSE, 2006).

On the grounds of these reasons, we assume that:

- there is an important correlation between the value of the power spectral density of an EEG-type signal taken at the level of the scalp and the inferential functions corresponding to the SPR potential measures at the same time, at the level of the palm of the same person, under the action of the same stimuli.

\subsection{Method, electronic equipment and measurement software}

In order to achieve the objectives of the research, we designed an electrodermal neurostimulator by means of which we applied at the level of the palms of the subject assessed, an electrodermal excitement signal, obtained by composing two signals: a step-type signal and a carrier signal; we received through an universal acquisition interface, type PC_LAB_2000SE, produced by Velleman, a response signal whose envelope contains essential information on 
the psycho-physiological processes on which we aimed to identify an inference. Thus, we expressed the projective response of the neurocortex, on each separate channel, in inferential functions, determined from information on the level of electrodermal activity, by means of identifying the electrodermal potential levels, stimulated in alternative current, SPL-type - base potential, and SPR-type - response potential. At the same time, we performed a simultaneous take-over, through an acquisition server interface, Open VIBE v1.2.2-type, from INRIA, of a set of EEG-type signals, at the level of the forehead of the same person, by means of using a professional headpiece, model Neuro Sky MindSet. Both the EDA-, and the EEG-type bio-signals were processed with the aid of an original software interface, for assessment with multiple stimuli, especially designed for this experiment, in order to be subjected to correlation, in values of power spectral density, but also to determine factor $\lambda$ and cognitive class $\mathrm{T}$. the diagram of the measurement system applied in this research is presented in Figure 4.

Figure 4: Block diagram of the measurement system

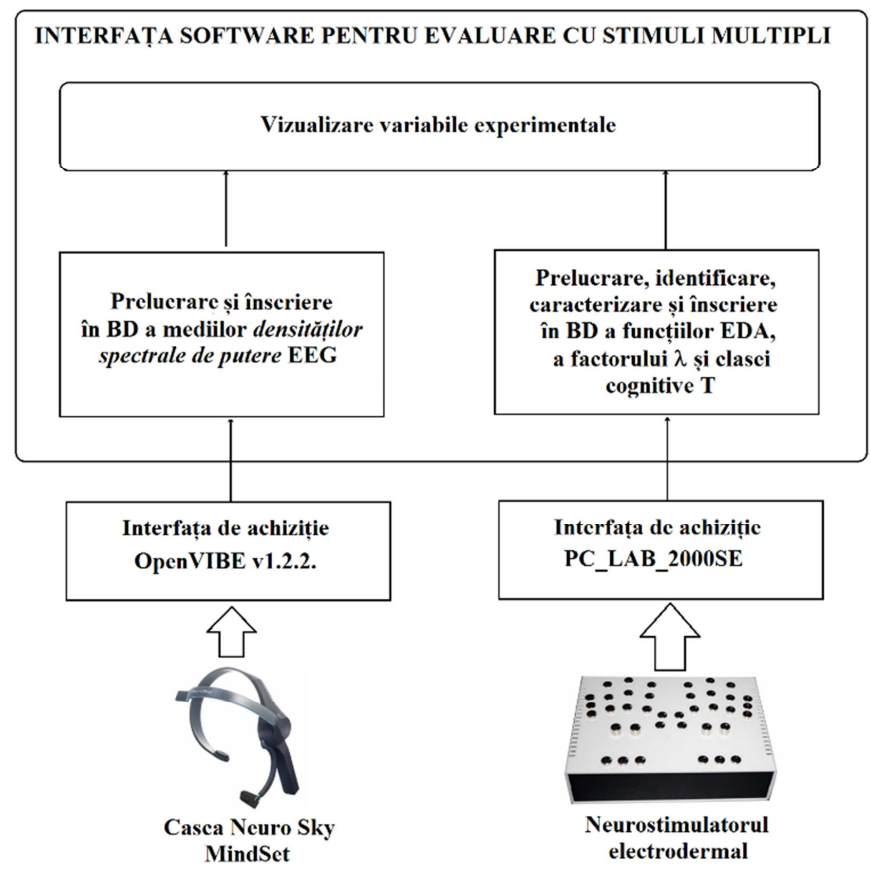

Source: author concept 


\subsection{Participants, variables, working procedure}

We performed the tests on a sample of 400 subjects with ages between 20 and 30 years old, irrespective of gender. Participation to the experiment occurred through voluntary option, each subject being informed regarding the conditions of the experiment.

We tested each subject in three stages of EEG - EDA simultaneous acquisition, through the consecutive use of distinct stimuli. Throughout the experiment, we followed, in case of the EDA electrodermal activity:

- independent variables: for stage 1, (STIMUL1, 2012), inferential function $X_{6}$, for stage 2, [STIMUL2, 2013], inferential function $X_{7}$, respectively, for stage 3, (STIMUL3, 2012), inferential function $X_{3}$;

- intermediary variables (internal states): the activity level of the psychophysiological functions; characteristic trait - electrodermal lability $\lambda$;

- dependent variables: the level of the SPR response electrodermal potential; frequency of electrodermal response events;

In case of EEG activity:

- independent variables: for Stimulus 1 , the induced state afferent to band $\beta$, for Stimulus 2 , the induced state afferent to band $\alpha$, respectively, for Stimulus 3 , the induced state afferent to band $\beta$ - high;

- intermediary variable (internal state): level of cortical activity;

- dependent variables: average of the power spectral density; for stage 1, variable DSP_BETA, for stage 2, variable DSP_ALFA, respectively, for stage 3, variable DSP_BETA_HIGH;

The final data analysis was performed with PASW Statistics 18.

5.4. Experimental results; analysis of the correlation between EEG-and EDA-type patterns

Hereinafter we shall present the results of the correlation analysis between the EDA inferential functions, respectively, $X_{6}, X_{3}$ and $X_{7}$ and the averages of the power spectral densities of the EEG bio-signals: DSP_BETA, DSP_BETA_HIGH and DSP_ALFA. 
Figure 5: Total item statistics

\begin{tabular}{|c|c|c|c|c|c|}
\hline & $\begin{array}{l}\text { Scale Mean if } \\
\text { Item Deleted }\end{array}$ & $\begin{array}{l}\text { Scale } \\
\text { Variance } \\
\text { if Item } \\
\text { Deleted }\end{array}$ & $\begin{array}{l}\text { Corrected } \\
\text { Item- } \\
\text { Total } \\
\text { Correlation }\end{array}$ & $\begin{array}{c}\text { Squared } \\
\text { Multiple } \\
\text { Correlation }\end{array}$ & $\begin{array}{c}\text { Cronbach's } \\
\text { Alpha Based } \\
\text { on } \\
\text { Standardized } \\
\text { Items }\end{array}$ \\
\hline$X \_6$ & 7.5779 & 1.032 & .883 & .780 & .938 \\
\hline DSP BETA & 100.5324 & 126.846 & .883 & .780 & \\
\hline$X \_7$ & 7.3358 & .973 & .872 & .761 & .932 \\
\hline DSP_ALFA & 97.4073 & 116.045 & .872 & .761 & \\
\hline$X \_3$ & 7.8387 & .490 & .826 & .682 & .905 \\
\hline DSP_BETA_HIGH & 100.6668 & 76.960 & .826 & .682 & \\
\hline
\end{tabular}

Source: author concept, 2016

The dispersion diagrams for the viewing of the relationship between the EDA-EEG pattern pairs with the linear association represented by the Pearson bivaried correlation and the square of the predictor variable in the linear regression $R^{2}$, are presented in Figure 6 .

Figure 6: Block diagram of the measurement system
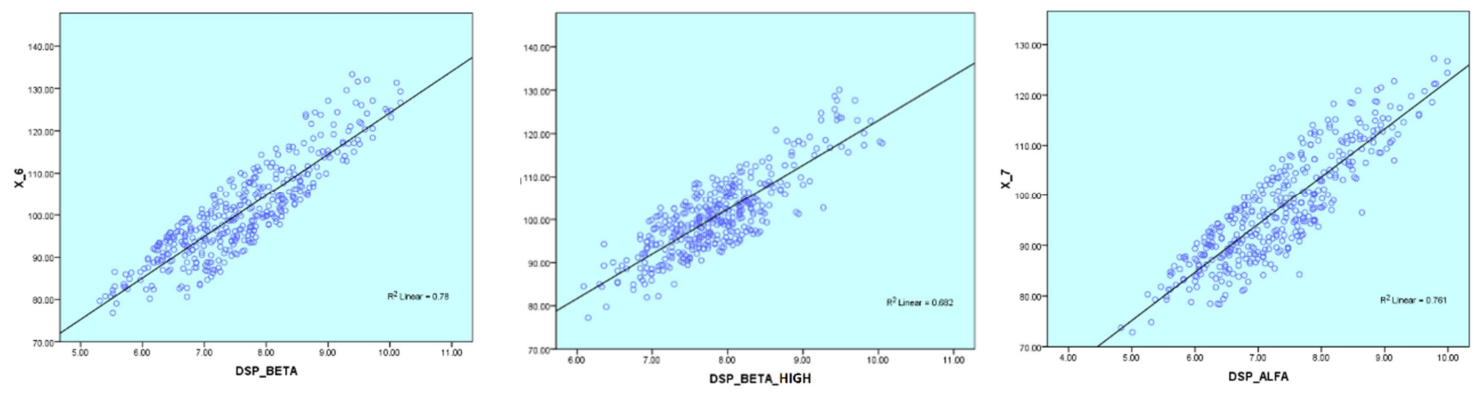

Source: author concept, 2016

\section{Conclusions}

From the correlation analysis, as well as from the form of the dispersion diagrams, it is derived that there is a strong correlation between the inferential functions and the average of the power spectral densities of the EEG bio-signals, respectively a 0.883 Pearson correlation for the variables pair $X_{6}$ - DSP_BETA, 0.826 for $X_{3}$ - DSP_BETA_HIGH and 0.872 for $X_{7}$ - DSP_ALPHA.

It is, therefore, confirmed that there is an important correlation between the power spectral density pattern of an EEG-type signal taken at the level of the scalp and the pattern of the response functions through EDA-type signal, taken at 
the level of the palm of the same person, through the phasic neurostimulation procedure.

The value of the inter-items correlation established for the action of Stimuli 1 and 2 confirms the act that, in the cognitive stage, the two equipment have responses with very close significations, (coefficient Alpha Cronbach for standardized items: 0.938 and 0.932 ). Also, in case of an emotional situation, the two equipment maintain the response with significances close to each other (coefficient Alpha Cronbach for standardized items: 0,905).

The differences expressed I slightly lower values of the correlation between stages can be explained through the technological difference through which the two instruments achieve the acquisition of biodata. The NeuroSky MindSet headpiece presents for the EEG-type signals a superimposition of numerous simple signals with amplitude, usually varying from approximately $1 \mu \mathrm{V}$ to $100 \mu \mathrm{V}$ in a normal adult and being approximately $10-20 \mathrm{mV}$, if measured with subdural electrodes, normally as the FFT electrodes would be, and the phasic neurostimulator measures the response electrical signals whose values can be seen between $18-435 \mathrm{mV}$, depending on the internal structure of the stimulation equipment. Hence, there is a functional difference between the EEG-type bio-signals, which we consider predominantly clinical interest biosignals, being connected to sub-systems with strictly specialized cerebral activity, and EDA-stimulated-type, which are psychological interest bio-signals, being possible to correlate with the sub-systems with integrated psychic activity. In fact, here resides the importance of using the cognitive patterns (EDA) in remote movement command and control.

\section{Bibliography}

[1] Block, J. (2002). Personality as an affect-processing system. Mahwah, NJ: Lawrence Erlbaum Associates.

[2] Boucsein, W. (2012). Electrodermal Activity, Second edition, New York: Springer Science + Business Media, LLC.

[3] Grigore D., \& Costache, G. C. (2015). Comparative study regarding GSR and EEG type biosignals simultaneously answer to same external stimulus, The International Conference Education and Creativity for a Knowledge based Society - Psychology, November 19nd-21rd, 2015, "Titu Maiorescu" University.

[4] Grigore, D. (2013). Echipament electronic și metodă pentru determinarea rapidă a profilului psihologic, RO127615, România: OSIM.

[5] Grigore, D. (2014). Sistem psihometric integrat pentru evaluare complementară, Pitești: Editura ARGEȘ PRESS. 
[6] Grigore, D. (2015). Procesarea biosemnalelor și corelarea dintre biosemnal și controlul mișcării la distanță - Raport de Cercetare Numărul 2, Doctoral School, Military Technical Academy, Bucharest.

[7] Grigore, D. (2015). Studiu statistic privind prelucrarea datelor experimentale ale interacțiunii dintre biosemnale și controlul mișcării la distanță - Raport de Cercetare Numărul 3, Doctoral School, Military Technical Academy, Bucharest, November.

[8] Grigore, D. (2016). Metodă fractală inferențială, Sesiunea Științifică a Academiei Oamenilor de Știință din România, Durău, 22-24 September 2016.

[9] Grigore, D., \& Petrescu, C. (2015). Multiple correlations between EEG and GSR patterns on remote movement command and control, International Conference Greener and Safer Energetic and Ballistic Systems, GSEBS 2015, held at the Military Technical Academy Bucharest, ROMANIA, May 22nd - 23rd, 2015.

[10] Grigore, D., Paraschiv, R. V., \&Anghelina, L. O. (2016). The action of multiple stimulations on GSR involved în remote movement command and control, International Conference Greener and Safer Energetic and Ballistic Systems, GSEBS 2016, held at the Military Technical Academy Bucharest, ROMANIA, May 26nd - 27rd, 2016.

[11] LAROUSSE. (2006). Marele dicționar al psihologiei, LAROUSSE, 407, Bucharest: Trei Publishing House.

[12] Öhman A., Hamm, A., \& Hugdahl, K. (2000). Cognition and the autonomic nervous system in J. T. Cacioppo, L. G. Tassinary, \& G. G. Berntson (Eds.), Handbook of psychophysiology (2nd ed). New York: Cambridge University Press.

[13] Paraschiv T., Grigore D., \& Constantin A. (2013). Modelarea neurosemnalelor electrodermice stimulate fazic, National Conference SISTEME ENERGETICE ŞI BALISTICE - SEB 2013, Military Technical Academy, Bucharest, 19-20 September 2013.

[14] Robins, R. W., John, O. P., Caspi, A., Moffitt, T. E., \& Stouthamer- Loeber, M. (1996). Resiliant, overcontrolled, and undercontrolled boys: Three replicable personality types. Journal of Personality and Social Psychology, 70, 157-171.

[15] STIMUL1. (2012). NASA MARS MISION, intechopen.com. Retrieved from: https://www.youtube.com/watch?v=oNviFQpRvwQ.

[16] STIMUL2. (2012). Relaxing Music - Meditation, youtube.com. Retrieved from: https://www.youtube.com/watch?v=qrx1vyvtRLY.

[17] STIMUL3. (2012). youtube.com, Retrieved https://www.youtube.com/watch?v=HpW5vGU2E9I. 